2000

\title{
Experimental and theoretical study of the photoelectron spectra of $\mathrm{MnOx}-(\mathrm{x}=1-3)$ clusters
}

Gennady L. Gutsev

Virginia Commonwealth University

B. K. Rao

Virginia Commonwealth University

P. Jena

Virginia Commonwealth University

Xi Li

Washington State University

Lai-Sheng Wang

Washington State University

Follow this and additional works at: http://scholarscompass.vcu.edu/phys_pubs

Part of the Physics Commons

Gutsev, G. L., Rao, B. K., Jena, P., et al. Experimental and theoretical study of the photoelectron spectra of $\mathrm{MnO} x-$ (x=1-3) clusters. The Journal of Chemical Physics 113, 1473 (2000). Copyright (C) 2000 AIP Publishing LLC.

\section{Downloaded from}

http://scholarscompass.vcu.edu/phys_pubs/151

This Article is brought to you for free and open access by the Dept. of Physics at VCU Scholars Compass. It has been accepted for inclusion in Physics Publications by an authorized administrator of VCU Scholars Compass. For more information, please contact libcompass@vcu.edu. 


\title{
Experimental and theoretical study of the photoelectron spectra of $\mathrm{MnO}_{x}^{-}(x=1-3)$ clusters
}

\author{
Gennady L. Gutsev, B. K. Rao, and P. Jena \\ Physics Department, Virginia Commonwealth University, Richmond, Virginia 23284-2000 \\ Xi Li and Lai-Sheng Wang \\ Department of Physics, Washington State University, 2710 University Drive, Richland, Washington 99352 \\ and W. R. Wiley Environmental Molecular Sciences Laboratory, Pacific Northwest National \\ Laboratory, MS K8-88, P.O. Box 999, Richland, Washington 99352
}

(Received 13 January 2000; accepted 24 April 2000)

\begin{abstract}
We report a combined experimental and theoretical investigation of $\mathrm{MnO}_{x}^{-}$and $\mathrm{MnO}_{x}(x=1-3)$ clusters. Theoretically, geometrical configurations of various isomers of the clusters were optimized and vertical detachment energies for the anions were evaluated. The ground state of $\mathrm{MnO}^{-}$was predicted to be ${ }^{5} \Sigma^{+}$, followed by an excited state $\left({ }^{7} \Sigma^{+}\right) 0.14 \mathrm{eV}$ higher in energy. The ground state of $\mathrm{MnO}_{2}^{-}$is ${ }^{5} B_{2}$, with a ${ }^{3} B_{1}$ isomer $0.15 \mathrm{eV}$ higher. $\mathrm{MnO}_{3}^{-}$is predicted to be a singlet $D_{3 h}$ cluster. Vibrationally resolved photoelectron spectra of $\mathrm{MnO}_{x}^{-}$were measured at several photon energies and under various experimental conditions, and were interpreted based on the theoretical results. The electron affinities of $\mathrm{MnO}, \mathrm{MnO}_{2}$, and $\mathrm{MnO}_{3}$ were determined to be 1.375 (0.010), 2.06 (0.03), and 3.335 (0.010), respectively. Five excited states of $\mathrm{MnO}$ were observed and assigned using the theoretical results. The ${ }^{7} \Sigma^{+}$excited state of $\mathrm{MnO}^{-}$was found to be significantly populated and was distinguished from the ground state of the anion by temperature dependent studies. We observed two isomers for $\mathrm{MnO}_{2}^{-}$and the detachment features from both isomers were assigned. Only one vibrationally resolved band was observed for $\mathrm{MnO}_{3}^{-}$, which corresponds to transitions from the ground state of $\mathrm{MnO}_{3}^{-}$to that of $\mathrm{MnO}_{3}$. The combined experimental and theoretical studies allow us to elucidate the complicated electronic and geometric structures of the various manganese oxide clusters and their anions. (C) 2000 American Institute of Physics. [S0021-9606(00)00428-1]
\end{abstract}

\section{INTRODUCTION}

Manganese oxides present an interesting class of compounds with important technological applications, ${ }^{1}$ in biological systems such as metallo-enzymes, ${ }^{2}$ and in catalysis. ${ }^{3}$ For example, permanganate anion, $\mathrm{MnO}_{4}^{-}$, is extensively used as an oxidizing agent and is a very common inorganic anion in solutions and solids. ${ }^{4}$ Its photochemical decomposition with evolution of molecular oxygen in alkaline-aqueous solutions has been observed long time ago. ${ }^{5}$ Although the bulk manganese oxide is antiferromagnetic, $\mathrm{Mn}_{x} \mathrm{O}_{y}$ clusters have been found to exhibit ferromagnetic or ferrimagnetic behavior. In addition, stoichiometric manganese oxide clusters $(\mathrm{MnO})_{n}$ have been found to possess giant magnetic moments which are localized primarily at Mn sites. ${ }^{6-9}$

Among manganese oxide clusters rich in oxygen, most experimental and theoretical efforts have been focused on the study of $\mathrm{MnO}_{4}^{-}$. Its equilibrium geometry $\left(T_{d}\right)$ and vibrational frequencies were obtained in salts. ${ }^{10,11}$ Experimental electronic absorption spectra of $\mathrm{MnO}_{4}^{-}$were measured in solutions $^{12,13}$ and have been extensively studied theoretically. ${ }^{14-20}$ Photodecomposition of $\mathrm{MnO}_{4}^{-}$in solutions has also been the subject of several experimental ${ }^{21-25}$ and theoretical studies. ${ }^{26,27} \mathrm{MnO}_{4}$ was found to possess very high electron affinity of $\sim 5 \mathrm{eV},{ }^{28,29}$ which puts it in the class of superhalogens, ${ }^{30}$ since the largest electron affinity of $3.62 \mathrm{eV}$ among all the atoms is that of halogen $\mathrm{Cl}^{31}$ Very few ex- perimental studies of $\mathrm{MnO}_{4}^{-}$in the gas phase have been reported so far in the literature. ${ }^{29,32-34}$

Experimental infrared and electron-spin-resonance data on neutral $\mathrm{MnO}_{x}(x=2-4)$ were obtained mainly in matrix isolation studies. ${ }^{35-38}$ However, assignments of geometric configurations of these species have been controversial. This could be due to the fact that all transition metal oxides appear to have a large number of isomers. For example, $\mathrm{MnO}_{4}$ has at least 10 isomers in the energy range of $2.8 \mathrm{eV},{ }^{27}$ whereas $\mathrm{MnO}_{3}$ has 8 isomers within $3.5 \mathrm{eV}$ energy range, and $\mathrm{MnO}_{2}$ has 11 isomers within $4.3 \mathrm{eV}$ energy range, as discovered in the current work.

The reasons for the existence of so many isomers are twofold. First, as shown schematically in Fig. 1, oxygen can be bound to a transition metal in several ways: dissociatively (typical $\mathrm{O}-\mathrm{O}$ distances are around $2.5-2.8 \AA$ ) or associatively either in a peroxo form (typical $\mathrm{O}-\mathrm{O}$ distances are 1.4-1.55 $\AA$ ) or a superoxo form (typical O-O distances are around $1.3 \AA$ ). The dissociative form is often reported as valence, high-valence, or inserted forms while the peroxo form is referred as "side-on," and the superoxo form as "'end-on.', 39 As given in Fig. 1, we represent the highvalent, peroxo, and superoxo forms as $\mathrm{OMO}, \mathrm{M}\left(\mathrm{O}_{2}\right)$, and MOO, respectively. Second, closely spaced energy levels near the highest occupied molecular orbital (HOMO) region originating from $d$-states of a transition metal atom permit transition metal oxide clusters to have a variety of different 


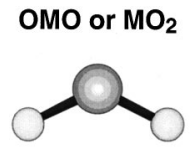

High-valent Inserted
Peroxo

Side-on

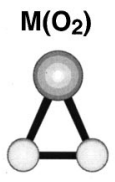

Superoxo

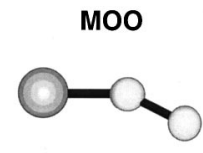

FIG. 1. The three general forms of bonding between a metal atom and $\mathrm{O}_{2}$.

spin-multiplicity states spaced within a narrow energy range. $^{40}$

The $\mathrm{MnO}$ monomer is the most studied among the manganese oxide species. Experimentally, its ground-state term was assigned and equilibrium bond length and vibrational frequency have been measured. ${ }^{41,42}$ However, its excited states are much less well known compared to other transition metal monoxides. ${ }^{43}$ The results of computations of the ground state of $\mathrm{MnO}$ using a pseudopotential method ${ }^{44}$ and the infinite-order coupled-cluster method with all singles and doubles and noniterative inclusion of triple excitations $[\operatorname{CCSD}(\mathrm{T})]$ (Ref. 45) were found to be in fair agreement with experimental measurements.

DFT calculations were reported previously for several isomers of $\mathrm{MnO}_{2} \cdot{ }^{38}$ No calculations on $\mathrm{MnO}_{3}$ or the $\mathrm{MnO}_{x}^{-}$ anions (except for the tetrahedral singlet ground state of $\mathrm{MnO}_{4}^{-}$, its peroxo isomer, and linear $\mathrm{MnO}_{2}^{-}$) have been reported yet in the literature. Experimental data on the $\mathrm{MnO}_{x}^{-}$ anions are also scarce. The enthalpies of formation for $\mathrm{MnO}_{2}^{-}$and $\mathrm{MnO}_{3}^{-}$and a vibrational frequency of $\mathrm{MnO}_{2}^{-}$ were reported. ${ }^{34,38}$ Interactions of these anions with molecular oxygen were also studied by mass spectroscopy. ${ }^{46}$

In recent years, laser photodetachment spectroscopy using high-energy photon beams has emerged as a powerful tool that can provide experimental information not only about the electronic structure of cluster anions, but also about the existence of lower-energy isomers. ${ }^{47-49}$ Using this technique, we have investigated a number of transition metal oxide systems, ${ }^{49-58}$ providing electronic and vibrational information that are otherwise either unavailable or difficult to obtain for these high temperature species. However, these species all have very complicated electronic structures and often yield rather congested photodetachment spectra. Detailed interpretation of these data requires accompanying computations by reliable quantum mechanical methods.

In this paper, we present the photodetachment spectra of $\mathrm{MnO}_{x}^{-}$obtained at several photon energies under variable experimental conditions, along with a comprehensive quantum theoretical analysis of their electronic structures in various geometrical and electronic configurations. While a single vibrational progression was observed for $\mathrm{MnO}_{3}^{-}$, extensive vibrational and low-lying electronic features were observed for $\mathrm{MnO}^{-}$and $\mathrm{MnO}_{2}^{-}$. Furthermore, we observed two anionic states for $\mathrm{MnO}^{-}$, and two structural isomers for $\mathrm{MnO}_{2}^{-}$. These electronic and structural isomers, confirmed by taking data at different source conditions, complicate considerably the interpretation of the observed photoelectron spectra. Computed electron affinities and vertical electron binding energies are used to help interpret the experimental results. Excellent agreement was obtained between the experimental and theoretical results, allowing us to completely elucidate the electronic and geometrical structures of the $\mathrm{MnO}_{x}^{-}$species and their neutral parents.

\section{COMPUTATIONAL AND EXPERIMENTAL DETAILS}

\section{A. Theoretical procedures}

The calculations are performed using the molecular orbital theory where linear combinations of atomic orbitals constitute one-electron molecular orbitals (MO). The manyelectron potential is constructed by using the densityfunctional theory (DFT) with the generalized gradient approximation for the exchange-correlation functional. A combination of Becke's exchange ${ }^{59}$ and Perdew-Wang's correlation functionals, ${ }^{60}$ referred to as BPW91, is used as implemented in the GAUSSIAN 94 software. ${ }^{61}$ For the atomic orbitals, we have used the standard $6-311+\mathrm{G}^{*}$ basis (Mn:[10s7p4d1f]; O:[5s4p1d]). These choices are known to yield results in very good agreement with a variety of experiments. ${ }^{27,62-64}$ Geometry optimizations were carried out by the steepest descent method until the gradient forces fell below the threshold value of $3 \times 10^{-4}$. Subsequent analytical harmonic frequency calculations were performed in order to confirm that the optimized geometries correspond to stationary states.

The density functional theory ${ }^{65-67}$ is valid for the lowest energy states in each particular symmetry (spatial and spin) channel. Since we have performed extensive optimizations beginning with different spatial configurations for each spin multiplicity for both $\mathrm{MnO}_{x}$ and $\mathrm{MnO}_{x}^{-}$series, we believe that the ground-state configurations are identified unambiguously. Comparison of properties of these states with experimental data provides a further confirmation for our assignment.

The relationship between the spin multiplicity $M=2 S$ +1 , and the number of electrons in the spin-up $\left(n_{\alpha}\right)$ and spin-down $\left(n_{\beta}\right)$ representations is given by

$$
2 S+1=\int\left[\rho^{\alpha}(r)-\rho^{\beta}(r)\right] d r=n_{\alpha}-n_{\beta}+1,
$$

where $\rho^{\alpha}$ and $\rho^{\beta}$ are the densities of electrons with $\alpha$ and $\beta$ spins and the total electron density is $\rho^{\alpha}+\rho^{\beta}$. The direct product of symmetries of partially occupied Kohn-Sham molecular orbitals defines spatial symmetry of a state described by a given electronic configuration.

Vertical binding energies ( $E_{b, i}$ or vertical ionization potentials), which are responsible for the features in photodetachment spectra, can be evaluated as

$$
E_{b, i}=E_{\mathrm{tot}}\left(A_{n}, R_{A}^{n}\right)-E_{\mathrm{tot}}\left(N, R_{A}^{n}\right)-\left(\epsilon_{i}^{A, n}, \epsilon_{\mathrm{HOMO}}^{A, n}\right),
$$

where $E_{\text {tot }}\left(A_{n}, R_{A}^{n}\right)$ and $E_{\text {tot }}\left(N, R_{A}^{n}\right)$ are total energies of the $n$th anion state and its lowest-energy neutral parent, respectively, at the equilibrium geometry $R_{A}^{n}$ of the $n$th anion state; $\epsilon_{i}^{A, n}$ is the orbital energy of the $i$ th molecular orbital in the $n$th anion state. Note that the lowest values of the $E_{b, i}$ 's are calculated "exactly," because the last term in the parentheses in Eq. (2) vanishes and all other $E_{b, i}$ 's are given by relative displacements of the corresponding eigenvalues. For 
high-multiplicity states, one can calculate directly the second $E_{b, i}$ as well, which provides an estimation of the accuracy anticipated from using Eq. (2).

By definition, the adiabatic electron affinity $\left(A_{\mathrm{ad}}\right)$ measures the energy gain in total energy of a system due to attachment of an additional electron and represents a very useful thermodynamic quantity. The $A_{\text {ad }}$ is given by the difference in the ground-state total energies of the neutral system and its anion. Within the Born-Oppenheimer approximation employed in the present work, the $A_{\mathrm{ad}}$ is

$$
\begin{aligned}
A_{\text {ad }} & =E_{\text {tot }}\left(N, R_{N}\right)+Z_{N}-E_{\text {tot }}\left(A, R_{A}\right)-Z_{A} \\
& =\Delta E_{\text {el }}+\Delta E_{\text {mic }},
\end{aligned}
$$

where $R_{N}$ and $R_{A}$ denote ground-state equilibrium bond lengths of a neutral molecule $(N)$ and its anion $(A)$, respectively. The zero-point vibration energies $(Z)$ are computed within the harmonic approximation. Usually, the $E_{b, i}$ 's correspond to features with the maximum or near-maximum intensities in the corresponding envelope of a photoelectron spectrum, whereas the $A_{\text {ad }}$ 's have to be deduced from a careful analysis of the spectrum. ${ }^{68,69}$

In order to estimate thermodynamic stability of manganese oxide clusters, we have evaluated their fragmentation channels with evolution of $\mathrm{O}$ and $\mathrm{O}_{2}$ in $\mathrm{MnO}_{x}$ or $\mathrm{O}^{-}$and $\mathrm{O}_{2}^{-}$ in $\mathrm{MnO}_{x}^{-}$. These fragmentation energies correspond to the differences in total energies of fragments $F_{i}$ formed in a particular decay channel and the total energy of an initial compound $M$,

$$
D_{e}(M)=\sum_{i} E_{\mathrm{tot}}\left(F_{i}\right)-E_{\mathrm{tot}}(M)
$$

\section{B. Experimental details}

The $\mathrm{MnO}_{x}^{-}$anions were generated by pulsed laser vaporization of a pure Mn disk target into a pulsed helium carrier gas seeded with $5 \% \mathrm{O}_{2}$. The plasma reactions between the laser vaporized $\mathrm{Mn}$ atoms and the oxygen formed the $\mathrm{MnO}_{x}^{-}$ species, which were entrained into the helium carrier gas and expanded through a $2 \mathrm{~mm}$ diam nozzle into the source vacuum chamber to form a supersonic cluster beam. The magnetic-bottle time-of-flight photoelectron spectrometer used for this study has been described in detail previously. ${ }^{47,49,70}$ Briefly, the negative clusters are extracted from the collimated cluster beam after one skimmer at $90^{\circ}$ and are mass analyzed by a time-of-flight mass spectrometer. The anions of interest were selected by a pulsed mass gate and decelerated by a momentum decelerator before crossing with a detachment laser beam in the interaction zone of the magnetic-bottle photoelectron apparatus. Photoelectrons were collected by the magnetic bottle at nearly $100 \%$ efficiency and were energy-analyzed by their time of flight in a 3.5-m-long flight tube. A Q-switched Nd:YAG laser [532 nm (2.331 eV), $355 \mathrm{~nm}(3.496 \mathrm{eV})$, and $266 \mathrm{~nm}(4.661 \mathrm{eV})]$ was used for photodetachment. At $266 \mathrm{~nm}$, spectra were taken at $20 \mathrm{~Hz}$ with the anion beam off at alternating laser shots for background subtraction. The electron time-of-flight spectra were converted to electron kinetic energy distributions, calibrated by the known spectra of $\mathrm{Cu}^{-}$. The kinetic energy
TABLE I. Equilibrium bond lengths $\left(R_{e}\right.$, in $\AA$ ), harmonic vibrational frequencies $\left(\omega_{e}\right.$ in $\left.\mathrm{cm}^{-1}\right)$, magnetic moments at $\mathrm{Mn}$ and $\mathrm{O}$ sites $\left(\mu_{A}\right.$ in $\left.\mu_{\text {Bohr }}\right)$, and dipole moments (DM in Debyes) of $\mathrm{MnO}$ and $\mathrm{MnO}^{-}$.

\begin{tabular}{lccccccc}
\hline \hline & \multicolumn{3}{c}{$\mathrm{MnO}$} & & \multicolumn{2}{c}{$\mathrm{MnO}^{-}$} \\
\cline { 2 - 3 } \cline { 6 - 7 } & ${ }^{6} \Sigma^{+}$ & ${ }^{6} \Sigma^{+} \mathrm{a}$ & ${ }^{6} \Sigma^{+}(\text {expt })^{\mathrm{b}}$ & & ${ }^{5} \Sigma^{+}$ & ${ }^{7} \Sigma^{+}$ \\
\hline$R_{e}$ & 1.628 & 1.658 & 1.648 & & 1.655 & 1.714 \\
$\omega_{e}$ & 898 & 779 & 840 & & 865 & 836 \\
$\mu_{\mathrm{Mn}}$ & 4.74 & $\cdots$ & $\cdots$ & & 3.85 & 5.72 \\
$\mu_{\mathrm{O}}$ & 0.26 & $\cdots$ & $\cdots$ & & 0.15 & 0.28 \\
$\mathrm{DM}$ & 4.36 & 4.99 & $\cdots$ & & 0.17 & 0.46 \\
\hline \hline
\end{tabular}

${ }^{\mathrm{a}} \operatorname{CCSD}(\mathrm{T})$ results are from Ref. 45 .

'Experimental $R_{e}$ and $\omega_{e}$ ("anharmonic" $\Delta G_{1 / 2}=832.4 \mathrm{~cm}^{-1}$ ) are from Ref. 42.

spectra were subtracted from the respective detachment photon energies to obtain the electron binding energy spectra. The resolution of the spectrometer was better than $30 \mathrm{meV}$ at $1 \mathrm{eV}$ kinetic energy. Better resolution is obtained when low photon energies are used; however, high photon energies allow more strongly bound electrons to be probed and are necessary for exploring clusters with high oxygen content due to their high EAs.

\section{RESULTS AND DISCUSSIONS}

\section{A. Electronic and geometric structure from theoretical calculations}

\section{1. $\mathrm{MnO}$ and $\mathrm{MnO}^{-}$}

We found that the ground state of $\mathrm{MnO}$ is indeed ${ }^{6} \Sigma^{+}$ with a $\left(9 \sigma^{1} 4 \pi^{2} 1 \delta^{2}\right)$ electronic configuration, in agreement with the known ground state of MnO. In Table I, we compare our results with previous experimental data and results of the $\operatorname{CCSD}(\mathrm{T})$ calculations by Bauschlicher and Maitre. ${ }^{45}$ As can be seen, the BPW91/6-311+ $\mathrm{G}^{*}$ level of theory provides rather reasonable values for the bond length, vibrational frequency, and dipole moment of $\mathrm{MnO}$. According to the Mulliken spin-density analysis, Mn carries the local moment of $4.74 \mu_{B}$, which is close to the value of $5 \mu_{B}$ for a free $\mathrm{Mn}$ atom.

The lowest electronic configuration of $\mathrm{MnO}^{-}$is $\left(9 \sigma^{2} 4 \pi^{2} 1 \delta^{2}\right)$ and corresponds to a ${ }^{5} \Sigma^{+}$state. Another ${ }^{7} \Sigma^{+}$ state with the electronic configuration $\left(10 \sigma^{1} 9 \sigma^{1} 4 \pi^{2} 1 \delta^{2}\right)$ was found to be higher in total energy by $0.14 \mathrm{eV}$. The extra electron enters two different $\sigma$-orbitals of $\mathrm{MnO}$ in the two anionic states, where the $9 \sigma \mathrm{MO}$ is mainly of Mn $3 d$ character and the $10 \sigma \mathrm{MO}$ is mainly of Mn $4 \mathrm{~s}$. According to the Mulliken charge distribution analysis, the charges on the atoms $(\mathrm{Mn}, \mathrm{O})$ are almost the same in the two anion states; $(-0.32,-0.67)$ in ${ }^{5} \Sigma^{+}$and $(-0.28,-0.72)$ in ${ }^{7} \Sigma^{+}$, whereas the neutral ground state has a $(+0.42,-0.42)$ charge distribution.

\section{2. $\mathrm{MnO}_{2}$ and $\mathrm{MnO}_{2}^{-}$}

The $\mathrm{MnO}_{2}$ ground state was found to be ${ }^{4} B_{1}$ with the electronic configuration $\left(11 a_{1}^{1} 10 a_{1}^{1} 1 a_{2}^{2} 4 b_{1}^{1} 6 b_{2}^{2}\right)$. The same state with similar geometry parameters and vibrational frequencies was assigned previously ${ }^{38}$ as the ground state of $\mathrm{MnO}_{2}$ at the B3LYP/6-311+ $\mathrm{G}^{*}$ level as well. The first ex- 


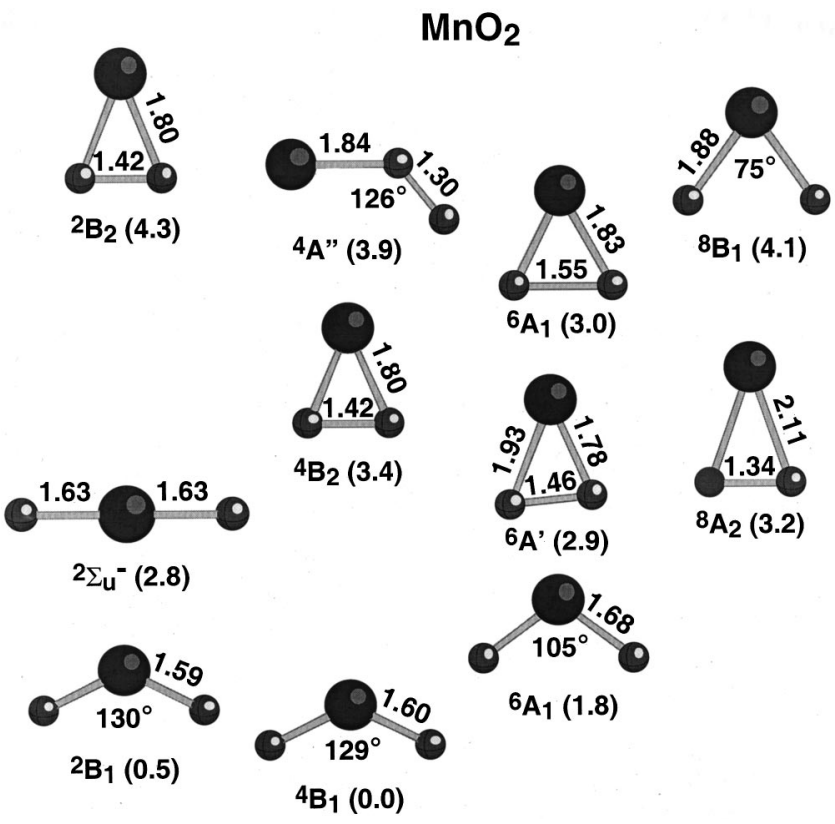

FIG. 2. High-valent, peroxo, and superoxo isomers of $\mathrm{MnO}_{2}$. Bond lengths are in $\AA$, bond angles are in deg. Relative displacements in total energy $(\mathrm{eV})$ with respect to the ground ${ }^{4} B_{1}$ state are given in the parentheses.

cited state of $\mathrm{MnO}_{2}$ is found to be ${ }^{2} B_{1}$ at both BPW91 and B3LYP levels, but the two methods give rather different geometrical parameters and relative energies. For example, the bond angle is $130^{\circ}$ at the BPW91 level, while it is $144^{\circ}$ at the B3LYP level. ${ }^{38}$ The $\mathrm{MnO}_{2}$ isomers of high valence (OMO), peroxo $\left[\mathrm{M}\left(\mathrm{O}_{2}\right)\right]$, and superoxo $(\mathrm{MOO})$ forms computed at the BPW91/6-311+ $\mathrm{G}^{*}$ level are presented in Fig. 2. We performed a search for lower energy states within each type of bonding and spin multiplicities and found 10 isomers of $\mathrm{MnO}_{2}$ that lie within $4.3 \mathrm{eV}$ of the ground state of $\mathrm{MnO}_{2}$. The anion has three states which are close in total energy, namely, ${ }^{3} B_{1}\left(11 a_{1}^{1} 10 a_{1}^{2} 1 a_{2}^{2} 4 b_{1}^{1} 6 b_{2}^{2}\right)$, ${ }^{3} A_{1}\left(11 a_{1}^{1} 10 a_{1}^{1} 1 a_{2}^{2} 4 b_{1}^{2} 6 b_{2}^{2}\right)$, ${ }^{5} B_{2}\left(11 a_{1}^{1} 10 a_{1}^{1} 1 a_{2}^{2} 2 a_{2}^{1} 4 b_{1}^{1} 6 b_{2}^{2}\right)$, formed by attachment of an extra electron to the $4 b_{1}(\beta), 10 a_{1}(\beta)$, and $2 a_{2}(\alpha)$ MO's of the ground-state neutral parent, respectively. The fourth anion state stable towards autodetachment of an extra electron is ${ }^{1} A_{1}$, see Table II and Fig. 3. A band at $858.2 \mathrm{~cm}^{-1}$ in

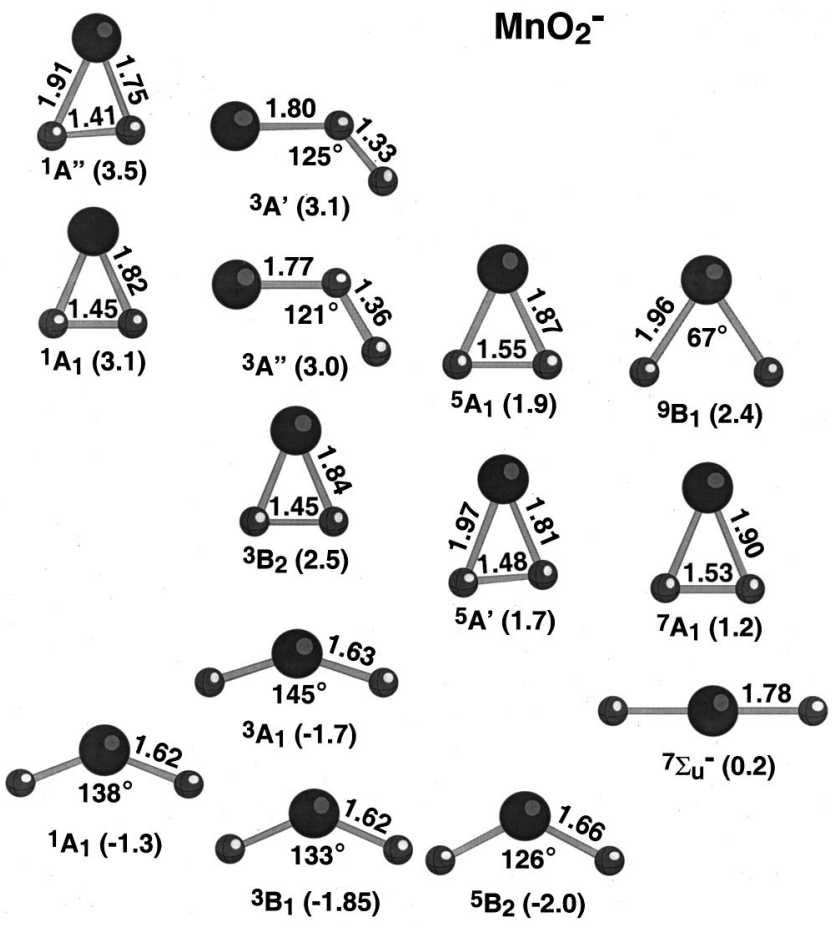

FIG. 3. High-valent, peroxo, and superoxo isomers of $\mathrm{MnO}_{2}^{-}$. Bond lengths are in $\AA$, bond angles are in deg. Relative displacements in total energy $(\mathrm{eV})$ with respect to the ground ${ }^{4} B_{1}$ state of the neutral $\mathrm{MnO}_{2}$ are given in the parentheses.

infrared absorption spectra, observed from reactions of laserablated $\mathrm{Mn}$ atoms and $\mathrm{O}_{2}$ molecules during condensation in excess argon at $10 \mathrm{~K},{ }^{38}$ was attributed to the $\nu_{3}$ fundamental $\left[\omega\left(b_{2}\right)\right]$ vibrational mode of $\mathrm{MnO}_{2}^{-}$. Our $\omega\left(b_{2}\right)$ harmonic vibrational frequencies for the ${ }^{3} B_{1}$ and ${ }^{5} B_{2}$ states are 882 and $873 \mathrm{~cm}^{-1}$, respectively. Since both of them are close to the experimental value, one can only tentatively conclude that the experimental frequency corresponds to the ground state of the $\mathrm{MnO}_{2}^{-}$anion.

Figure 3 displays different isomers of $\mathrm{MnO}_{2}^{-}$that are stable with respect to both autodetachment and fragmentation. The relative energies and structural parameters of these isomers are also shown. The key conclusion from Figs. 2 and 3 is that the $\mathrm{MnO}_{2}$ system prefers the high valent dioxide

TABLE II. Equilibrium bond lengths $\left(R_{e}\right.$ in $\AA$ ), bond angles ( $\angle \mathrm{OMO}$ in deg), harmonic vibrational frequencies $\left(\omega_{e}\right.$ in $\left.\mathrm{cm}^{-1}\right)$, differences in total energies $\left(\Delta E_{\text {tot }}\right.$ in $\mathrm{eV}$, relative to -1301.57312 hartree), magnetic moments at $\mathrm{Mn}$ and $\mathrm{O}$ sites $\left(\mu_{\mathrm{A}}\right.$ in $\mu_{\text {Bohr }}$ ), and dipole moments (DM in Debyes) of $\mathrm{MnO}_{2}$ and $\mathrm{MnO}_{2}^{-}$, in different electronic states and multiplicities.

\begin{tabular}{|c|c|c|c|c|c|c|c|c|}
\hline & \multicolumn{4}{|c|}{$\mathrm{MnO}_{2}$} & \multicolumn{4}{|c|}{$\mathrm{MnO}_{2}^{-}$} \\
\hline & ${ }^{2} B_{1}$ & ${ }^{4} B_{1}$ & ${ }^{4} B_{1}{ }^{\mathrm{a}}$ & ${ }^{6} A_{1}$ & ${ }^{1} A_{1}$ & ${ }^{3} A_{1}$ & ${ }^{3} B_{1}$ & ${ }^{5} B_{2}$ \\
\hline$R_{e}$ & 1.587 & 1.597 & 1.596 & 1.684 & 1.620 & 1.632 & 1.621 & 1.663 \\
\hline$\angle \mathrm{OMO}$ & 130.0 & 128.8 & 131 & 104.6 & 137.7 & 145.5 & 133.6 & 126.3 \\
\hline$\omega\left(a_{1}\right)$ & 229 & 261 & 243 & 173 & 221 & 198 & 226 & 240 \\
\hline$\omega\left(a_{1}\right)$ & 954 & 918 & 888 & 817 & 884 & 856 & 953 & 827 \\
\hline$\omega\left(b_{2}\right)$ & 1020 & 1012 & 995 & 438 & 950 & 937 & 882 & 873 \\
\hline$\Delta E_{\text {tot }}$ & +0.46 & 0.0 & $\ldots$ & +1.81 & -1.31 & -1.70 & -1.85 & -2.06 \\
\hline$\mu_{\mathrm{Mn}}$ & 1.20 & 3.14 & $\cdots$ & 3.54 & -0.18 & 2.26 & 2.18 & 3.86 \\
\hline$\mu_{\mathrm{O}}$ & -0.10 & -.07 & $\ldots$ & 0.73 & +0.09 & -0.13 & -0.09 & 0.07 \\
\hline
\end{tabular}

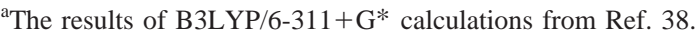




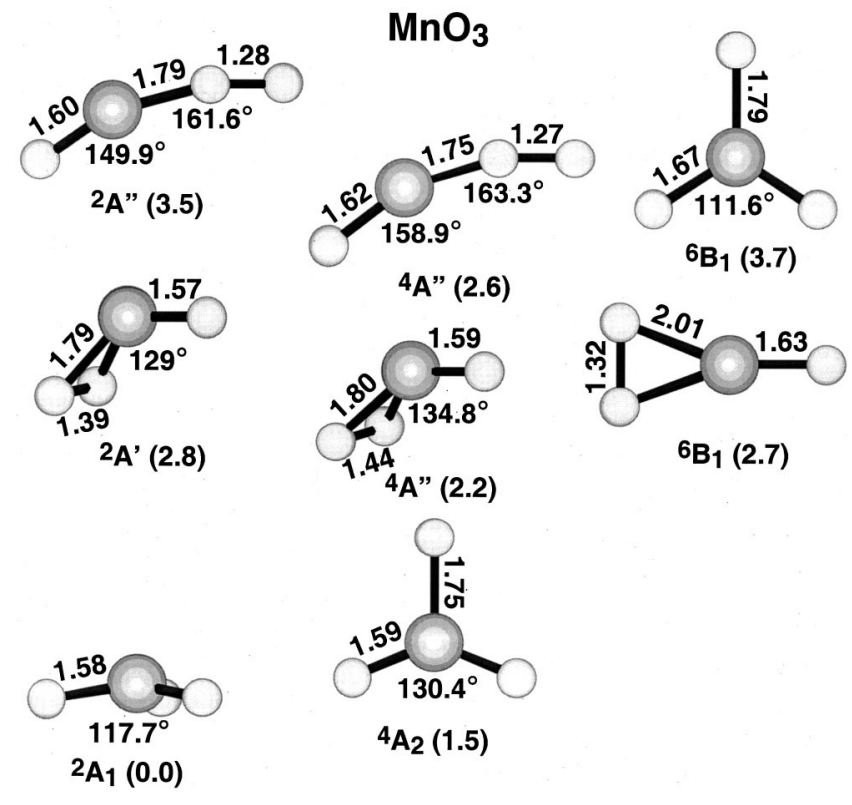

FIG. 4. Geometrical configurations of the neutral $\mathrm{MnO}_{3}$ isomers. Bond lengths are in $\AA$ and bond angles are in deg. Energy displacements in eV relative to the ground ${ }^{2} A_{1}$ state are given in the parentheses. Harmonic vibrational frequencies (in $\mathrm{cm}^{-1}$ ) are as follows. High-valent: ${ }^{2} A_{1}: \omega\left(a_{1}\right)$ $=151,926, \omega(e)=347,1024 ;{ }^{4} A_{2}: \omega\left(b_{1}\right)=84, \omega\left(b_{2}\right)=139,922, \omega\left(a_{1}\right)$ $=250,625,915 ;{ }^{6} B_{2}: \omega\left(b_{2}\right)=140, \omega\left(a_{1}\right)=169,393,775, \omega\left(b_{1}\right)=170$; Peroxo: ${ }^{2} A^{\prime}: \omega\left(a^{\prime}\right)=176,549,986,1029, \omega\left(a^{\prime \prime}\right)=214,550 ;{ }^{4} A^{\prime \prime}: \omega\left(a^{\prime}\right)$ $=168,568,905,995, \omega\left(a^{\prime \prime}\right)=189,498 ;{ }^{6} B_{1}: \omega\left(b_{2}\right)=44,474, \omega\left(b_{1}\right)$ $=131, \omega\left(a_{1}\right)=431,915,1153$; Superoxo: ${ }^{2} A^{\prime \prime}: \omega\left(a^{\prime}\right)=54,321,533,965$, $1335, \omega\left(a^{\prime \prime}\right)=289 ;{ }^{4} A^{\prime \prime}: \omega\left(a^{\prime}\right)=57,357,470,945,1336, \omega\left(a^{\prime \prime}\right)=339$.

form in both its neutral and anionic states. The peroxo or superoxo isomers all have much higher energies.

\section{3. $\mathrm{MnO}_{3}$ and $\mathrm{MnO}_{3}^{-}$}

The ground state of $\mathrm{MnO}_{3}$ is found to have $C_{3 v}$ symmetry with a $\left(10 a_{1}^{1} 1 a_{2}^{2} 7 e^{4}\right)$ electronic configuration corresponding to a ${ }^{2} A_{1}$ state. Optimized peroxo and superoxo isomers together with high-valent states of different multiplicities are given in Fig. 4; harmonic vibrational frequencies are given in the caption. Infrared bands at 1092.2 and $1090.2 \mathrm{~cm}^{-1}$ observed in the previous matrix experiment were assigned to $\left(\mathrm{O}_{2}\right) \mathrm{MnO}$ isomers. ${ }^{38}$ According to our calculations, the ${ }^{2} A^{\prime}$ peroxo isomer of $\mathrm{MnO}_{3}$ possesses a vibrational frequency of $1029 \mathrm{~cm}^{-1}$, which is in reasonable agreement with the previous experimental findings. One can see the presence of seven isomers of $\mathrm{MnO}_{3}$ within a $3.7 \mathrm{eV}$ energy range.

The ground state of the $\mathrm{MnO}_{3}^{-}$anion is a singlet ${ }^{1} A_{1}^{\prime}$ state and has $D_{3 h}$ symmetry, with an electronic configuration, $\left(7 a_{1}^{\prime}\right)^{2}\left(6 e^{\prime}\right)^{4}\left(3 a_{2}^{\prime \prime}\right)^{2}\left(1 e^{\prime \prime}\right)^{2}\left(1 a_{2}^{\prime}\right)^{2}$. As shown in Fig. 5, the lowest triplet state $\left({ }^{3} A_{2}\right)$ of the anion has a $C_{2 v}$ configuration $\left(13 a_{1}^{1} 2 a_{2}^{1} 4 b_{1}^{2} 7 b_{2}^{2}\right)$ and is above the ground state by $0.33 \mathrm{eV}$. The anion has two additional quintet states which are stable towards autodetachment, one of which has a peroxo form. There are four other anion isomers in Fig. 5 which are stable towards decay to the corresponding parent neutral states.

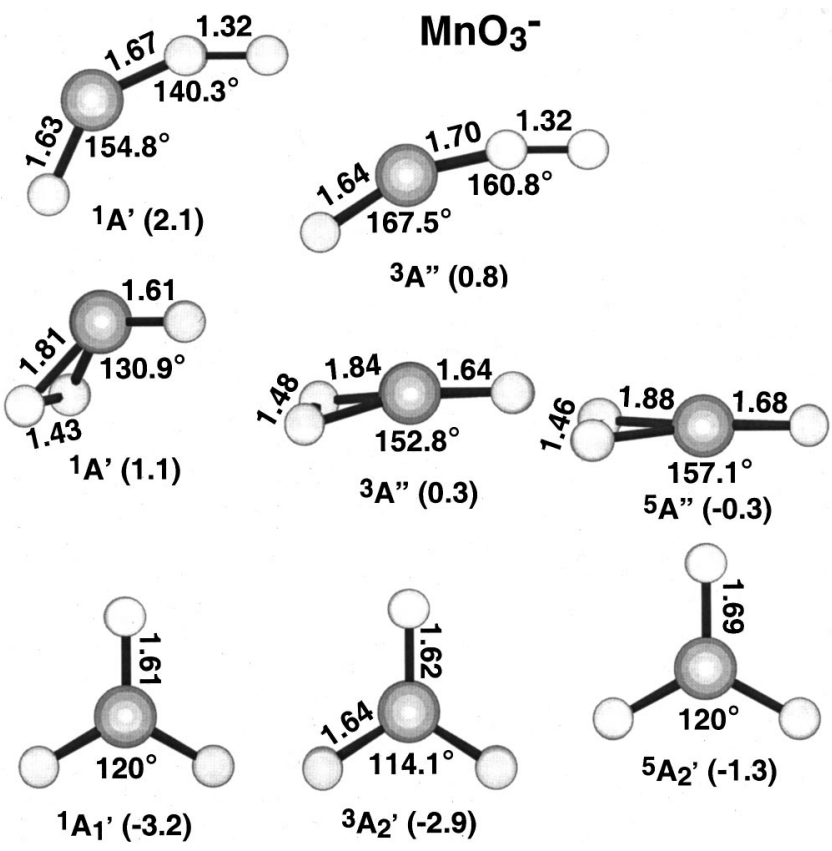

FIG. 5. Geometrical configurations of the $\mathrm{MnO}_{3}^{-}$isomers. Bond lengths are in $\AA$ and bond angles are in deg. Energy displacements in eV relative to the ground ${ }^{2} A_{1}$ state of the neutral $\mathrm{MnO}_{3}$ are given in the parentheses. Harmonic vibrational frequencies (in $\mathrm{cm}^{-1}$ ) are as follows. High-valent: ${ }^{1} A_{1}^{\prime}: \omega\left(a_{2}^{\prime \prime}\right)=158, \quad \omega\left(e^{\prime}\right)=327, \quad 970, \quad \omega\left(a_{2}^{\prime}\right)=881 ; \quad{ }^{3} A_{2}: \omega\left(b_{1}\right)=158$, $\omega\left(b_{2}\right)=176,791, \omega\left(a_{1}\right)=331,835,951 ;{ }^{5} A_{2}^{\prime}: \omega\left(a_{2}^{\prime \prime}\right)=128, \omega\left(e^{\prime}\right)=216$, 568, $\omega\left(a_{2}^{\prime}\right)=766$; Peroxo: ${ }^{1} A^{\prime}: \omega\left(a^{\prime \prime}\right)=174,474, \omega\left(a^{\prime}\right)=197,607,921$, 954; ${ }^{3} A^{\prime \prime}: \omega\left(a^{\prime}\right)=78,534,841,895, \omega\left(a^{\prime \prime}\right)=126,440 ;{ }^{5} A^{\prime \prime}: \omega\left(a^{\prime \prime}\right)=94$, 545, $\omega\left(a^{\prime}\right)=133,508,827,878$; Superoxo: ${ }^{1} A^{\prime}: \omega\left(a^{\prime}\right)=121,381,576$, 899, 1196, $\omega\left(a^{\prime}\right)=245 ;{ }^{3} A^{\prime \prime}: \omega\left(a^{\prime}\right)=66,364,516,871,1197, \omega\left(a^{\prime \prime}\right)$ $=343$.

\section{B. Theoretical vertical detachment energies and thermodynamic stability}

To facilitate comparison with the experimental photoelectron data, we have computed vertical detachment energies for all low-lying isomers of $\mathrm{MnO}^{-}, \mathrm{MnO}_{2}^{-}$, and $\mathrm{MnO}_{3}^{-}$, according to Eq. (2). The accuracy of this formula depends on the difference in relaxation energies when the extra electron is detached from various molecular orbitals. In order to assess the accuracy, we compare the values obtained using Eq. (2) with those computed as the differences in total energies for different states of $\mathrm{MnO}_{2}^{-}$and $\mathrm{MnO}_{3}^{-}$. Direct computations provide values of $3.94\left({ }^{6} A_{1}\right), 2.37\left({ }^{2} B_{1}\right), 2.30$ $\left({ }^{2} B_{1}\right) \mathrm{eV}$ for ${ }^{5} B_{2},{ }^{3} B_{1}$, and ${ }^{3} A_{1}$ states of $\mathrm{MnO}_{2}^{-}$, and 4.68 $\left({ }^{2} B_{2}\right) \mathrm{eV}$ of $\mathrm{MnO}_{3}^{-}$, whereas estimates using Eq. (2) are $4.28,2.61,2.57$, and $4.49 \mathrm{eV}$, respectively. Here, the maximum discrepancy is $0.3 \mathrm{eV}$, although this discrepancy might be anticipated to increase for highly localized states.

Fragmentation energies of both the neutral and anions are evaluated according to Eq. (4) and presented in Table III. Experimental data are known for $\mathrm{MnO}$ only. ${ }^{41}$ The BPW91/6-311+ $\mathrm{G}^{*}$ value of $5.4 \mathrm{eV}$ is overestimated with respect to the experimental value of $3.83(0.08)$ by more than $1 \mathrm{eV}$, which is typical for DFT methods. The most facile fragmentation channel for the neutral clusters $\left(\mathrm{MnO}_{2}\right.$ and $\mathrm{MnO}_{3}$ ) corresponds to evolution of molecular oxygen, whereas the anions prefer to yield either $\mathrm{O}^{-}\left(\mathrm{MnO}_{2}^{-}\right)$or $\mathrm{O}\left(\mathrm{MnO}_{3}^{-}\right)$. The anions are considerably more stable than 
TABLE III. Fragmentation energies $\left(D_{e}\right.$ in eV) of $\mathrm{MnO}_{x}$ and $\mathrm{MnO}_{x}^{-}$, computed according to Eq. (4).

\begin{tabular}{|c|c|c|c|}
\hline \multicolumn{2}{|l|}{$\mathrm{MnO}_{x}$} & \multicolumn{2}{|l|}{$\mathrm{MnO}_{x}^{-}$} \\
\hline & $D_{e}$ & & $D_{e}$ \\
\hline $\mathrm{MnO} \rightarrow \mathrm{Mn}+\mathrm{O}$ & 5.4 & $\begin{aligned} \mathrm{MnO}^{-} & \rightarrow \mathrm{MnO}+e \\
& \rightarrow \mathrm{Mn}+\mathrm{O}^{-}\end{aligned}$ & $\begin{array}{l}1.1 \\
4.8\end{array}$ \\
\hline $\begin{aligned} \mathrm{MnO}_{2} & \rightarrow \mathrm{Mn}+\mathrm{O}_{2} \\
& \rightarrow \mathrm{MnO}+\mathrm{O}\end{aligned}$ & $\begin{array}{l}4.7 \\
5.1\end{array}$ & $\begin{aligned} \mathrm{MnO}_{2}^{-} & \rightarrow \mathrm{MnO}_{2}+e \\
& \rightarrow \mathrm{MnO}^{-} \mathrm{O}^{-} \\
& \rightarrow \mathrm{MnO}^{-}+\mathrm{O} \\
& \rightarrow \mathrm{Mn}+\mathrm{O}_{2}^{-}\end{aligned}$ & $\begin{array}{l}2.0 \\
5.5 \\
6.1 \\
6.2\end{array}$ \\
\hline $\begin{aligned} \mathrm{MnO}_{3} & \rightarrow \mathrm{MnO}+\mathrm{O}_{2} \\
& \rightarrow \mathrm{MnO}_{2}+\mathrm{O}\end{aligned}$ & $\begin{array}{l}4.2 \\
4.9\end{array}$ & $\begin{aligned} \mathrm{MnO}_{3}^{-} & \rightarrow \mathrm{MnO}_{3}+e \\
& \rightarrow \mathrm{MnO}_{2}^{-}+\mathrm{O} \\
& \rightarrow \mathrm{MnO}_{2}+\mathrm{O}^{-} \\
& \rightarrow \mathrm{MnO}^{-}+\mathrm{O}_{2} \\
& \rightarrow \mathrm{MnO}+\mathrm{O}_{2}^{-}\end{aligned}$ & $\begin{array}{l}3.2 \\
6.1 \\
6.5 \\
6.4 \\
6.9\end{array}$ \\
\hline
\end{tabular}

their neutral parents towards fragmentation, although the lowest energy decay channel in the anions corresponds to detachment of an extra electron.

\section{Experimental results}

\section{1. $\mathrm{MnO}^{-}$}

The photoelectron spectra of $\mathrm{MnO}^{-}$taken at three photon energies and under two different experimental conditions are presented in Figs. 6 and 7. The "hot"' spectra were taken for anions that left the cluster nozzle early and experienced fewer collisions with the helium background gas. The "cold" spectra correspond to anions that left the nozzle later and received slightly better cooling. Our recent study of $\mathrm{Al}_{n}^{-}$ clusters have shown that cluster temperatures can vary from $200 \mathrm{~K}$ for the "cold" conditions to $900 \mathrm{~K}$ for the "hot", conditions based on comparisons of molecular dynamics simulations with temperature-dependent photoelectron spectra of small $\mathrm{Al}_{n}^{-}$clusters. ${ }^{71,72}$ However, the $\mathrm{MnO}^{-}$anions cannot be cooled as effectively as the $\mathrm{Al}_{n}^{-}$clusters because the time window during which the $\mathrm{MnO}^{-}$anions were abundant from our nozzle was relatively narrow. As we will show below from Franck-Condon simulations, the temperature of even the cold $\mathrm{MnO}^{-}$was still fairly high.

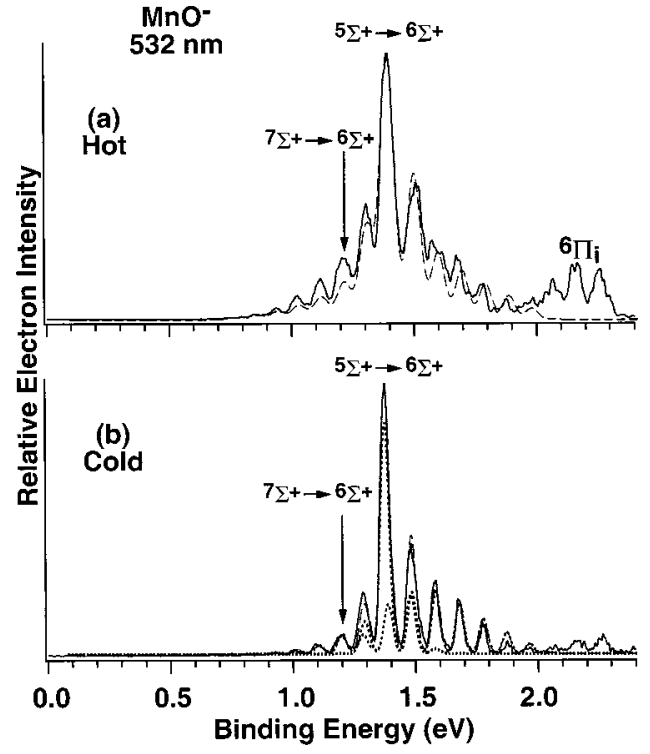

FIG. 6. Photoelectron spectra of $\mathrm{MnO}^{-}$at $532 \mathrm{~nm}(2.331 \mathrm{eV})$. (a) Under "hot" experimental conditions; (b) under "cold" experimental conditions. The dashed curves are results from Franck-Condon simulations. The dotted curves in (b) indicate the relative contributions from the two anionic states (see text).

The photoelectron spectra of $\mathrm{MnO}^{-}$reveal numerous detachment features with well-resolved vibrational progressions. Rather dramatic temperature effects were observed. While the number of features remained the same in the "hot" and "cold" spectra, the relative intensities of different peaks exhibited very different temperature dependence, suggesting that there were more than one type of $\mathrm{MnO}^{-}$ present in the beam, and their relative populations were different at the two experimental conditions. Since $\mathrm{MnO}^{-}$cannot have any structural isomers, the only possibility is that the beam contained electronically excited $\mathrm{MnO}^{-}$. Although we have observed electronically excited anions in our previous works, ${ }^{54,57,58,73}$ they usually had rather low abundance, producing only minor photoelectron features. The spectra of $\mathrm{MnO}^{-}$indicate that the excited anion had a substantial population, implying that it is probably nearly degenerate with the anion ground state. Based on the theoretical calculations, all

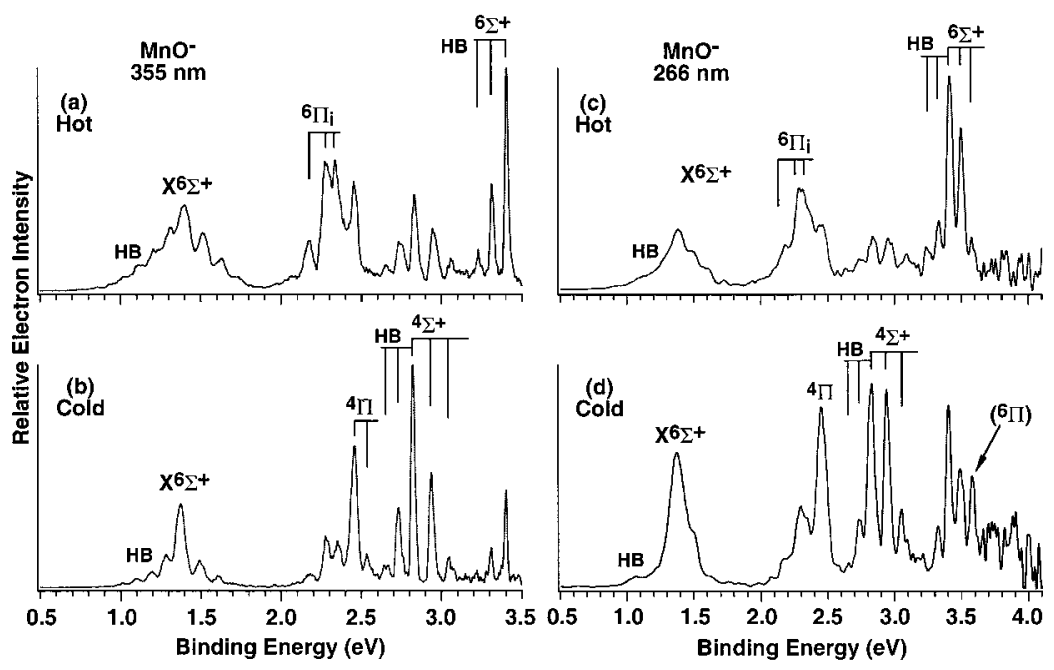

FIG. 7. Photoelectron spectra of $\mathrm{MnO}^{-}$at $355 \mathrm{~nm}$ $(3.496 \mathrm{eV})$ and $266 \mathrm{~nm}(4.661 \mathrm{eV})$. (a) at $355 \mathrm{~nm}$ and under "hot" experimental conditions; (b) at $355 \mathrm{~nm}$ and under "cold" experimental conditions; (c) at 266 $\mathrm{nm}$ and under "hot" experimental conditions; (d) at $266 \mathrm{~nm}$ and under "cold" experimental conditions. "HB" indicates hot band transitions. 
TABLE IV. Vertical electron binding energies $\left(E_{b, i}\right)$ from the two lowestenergy states of $\mathrm{MnO}^{-}$obtained by correcting orbital eigenvalues $\left(\varepsilon_{i}\right)$ according to Eq. (2), together with symmetries of neutral $\mathrm{MnO}$ formed after detachment from a particular MO (final states or FS) of the anion. Experimental vertical binding energies $\left[E_{b}\right.$ (expt.)], excitation energies $(\Delta E)$, and vibrational frequencies are also listed. All energies are in $\mathrm{eV}$ and vibrational frequencies are in $\mathrm{cm}^{-1}$.

\begin{tabular}{|c|c|c|c|c|c|c|}
\hline MO (spin) & $\varepsilon_{i}$ & $E_{b, i}$ & FS & $E_{b}$ (expt.) & $\Delta E$ & Freq (expt.) \\
\hline \multicolumn{7}{|c|}{$\mathrm{MnO}^{-5} \Sigma^{+} 0.0 \mathrm{eV}, E_{\mathrm{tot}}=-1226.34627$} \\
\hline $9 \sigma(\beta)$ & +0.98 & 1.05 & ${ }^{5} \Sigma^{+}$ & $1.375(0.01)$ & 0.00 & $820(40)$ \\
\hline $4 \pi(\alpha)$ & +0.33 & 1.70 & ${ }^{4} \Pi$ & $2.45(0.01)$ & 1.08 & $660(60)$ \\
\hline $9 \sigma(\alpha)$ & -0.11 & 2.14 & ${ }^{4} \Sigma^{+}$ & $2.82(0.01)$ & 1.45 & $920(40)$ \\
\hline $3 \pi(\beta)$ & -1.50 & 3.53 & ${ }^{6} \Pi$ & $3.58(0.04)$ & 2.21 & \\
\hline $1 \delta(\alpha)$ & -1.58 & 3.61 & ${ }^{4} \Delta$ & & & \\
\hline $8 \sigma(\beta)$ & -2.47 & 4.50 & ${ }^{6} \Sigma^{+}$ & & & \\
\hline $3 \pi(\alpha)$ & -2.83 & 4.86 & ${ }^{4} \Pi$ & & & \\
\hline $8 \sigma(\alpha)$ & -3.18 & 5.21 & ${ }^{4} \Sigma^{+}$ & & & \\
\hline \multicolumn{7}{|c|}{$\mathrm{MnO}^{-},{ }^{7} \Sigma^{+}, 0.14 \mathrm{eV}$} \\
\hline $10 \sigma(\alpha)$ & +1.44 & 1.02 & ${ }^{6} \Sigma^{+}$ & $1.22(0.04)$ & 0.00 & \\
\hline \multirow[t]{3}{*}{$4 \pi(\alpha)$} & +0.46 & 2.00 & ${ }^{6} \Pi_{i}$ & $2.18(0.03)$ & 0.96 & \\
\hline & & & & $2.27(0.02)$ & & \\
\hline & & & & $2.34(0.02)$ & & \\
\hline $9 \sigma(\alpha)$ & -0.52 & 2.98 & ${ }^{6} \Sigma^{+}$ & $3.40(0.02)$ & 2.18 & $730(60)$ \\
\hline $3 \pi(\beta)$ & -0.82 & 3.28 & ${ }^{8} \Pi$ & & & \\
\hline $9 \sigma(\beta)$ & -1.44 & 3.90 & ${ }^{8} \Sigma^{+}$ & & & \\
\hline $1 \delta(\alpha)$ & -1.71 & 4.17 & ${ }^{6} \Delta$ & & & \\
\hline $3 \pi(\alpha)$ & -2.34 & 4.80 & ${ }^{6} \Pi$ & & & \\
\hline $8 \sigma(\alpha)$ & -2.69 & 5.15 & ${ }^{6} \Sigma^{+}$ & & & \\
\hline
\end{tabular}

the features can be qualitatively assigned. Experimental binding energies along with theoretical vertical binding energies are given in Table IV. All the observed adiabatic transitions coincide with the vertical transitions judged from the appearance of the observed vibrational progressions, i.e., the vertical binding energies are equivalent to the adiabatic binding energies. The derived excitation energies for the excited states of neutral $\mathrm{MnO}$ and their vibrational frequencies are also given in Table IV along with the theoretical vertical binding energies.

\section{2. $\mathrm{MnO}_{2}^{-}$and $\mathrm{MnO}_{3}^{-}$}

The spectra of $\mathrm{MnO}_{2}^{-}$obtained at 355 and $266 \mathrm{~nm}$ under the two different experimental conditions are shown in Fig.
TABLE V. Experimental adiabatic $\left(A_{\text {ea }}\right)$ and vertical $\left(E_{b}\right)$ binding energies from the two $\mathrm{MnO}_{2}^{-}$isomers and the measured vibrational frequencies for the $\mathrm{MnO}_{2}$ neutral states, compared to the corresponding theoretical values.

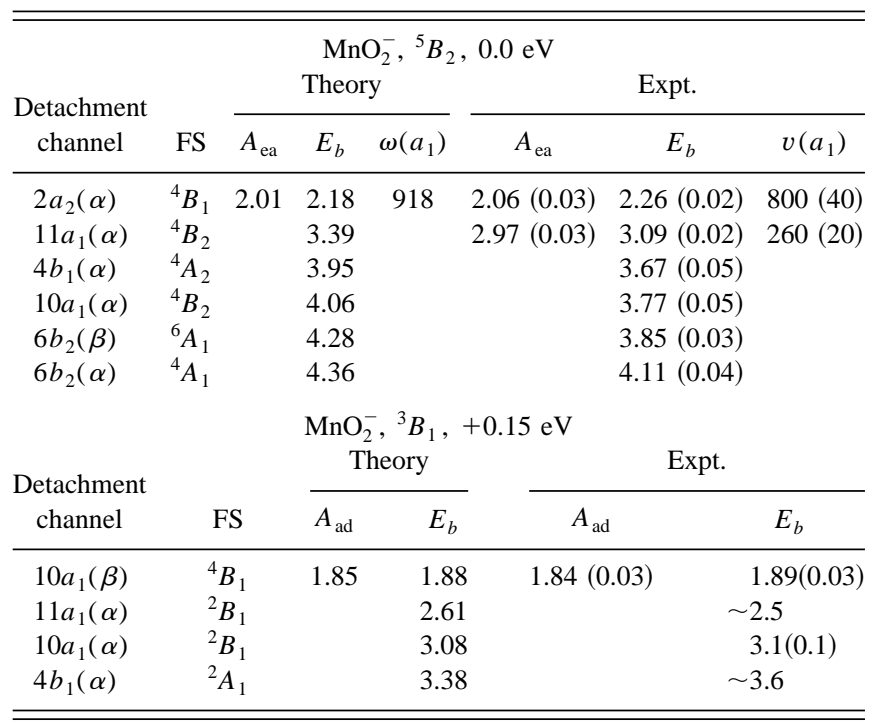

8. Significant temperature effects were observed for the $\mathrm{MnO}_{2}^{-}$spectra as well. Here the "cold" spectra showed sharp and vibrationally resolved features, whereas the "hot" spectra yielded very broad features. By comparison with the theoretical results, a higher energy isomer of $\mathrm{MnO}_{2}^{-}$was identified to be present. Our measured adiabatic and vertical binding energies and the vibrational frequencies are listed in Table $\mathrm{V}$ and compared to the corresponding theoretical values.

The spectrum of $\mathrm{MnO}_{3}^{-}$is shown in Fig. 9, and was taken only at $266 \mathrm{~nm}$ because of its relatively high binding energy. A single vibrationally resolved band was observed for $\mathrm{MnO}_{3}^{-}$. The spectrum of $\mathrm{MnO}_{3}^{-}$showed no significant temperature effects except that the features became slightly broader at the "hot" conditions. The electron binding energy was measured to be $3.335(0.010) \mathrm{eV}$ and the observed vibrational frequency is $840(50) \mathrm{cm}^{-1}$, as given in Table VI and compared to the theoretical values.

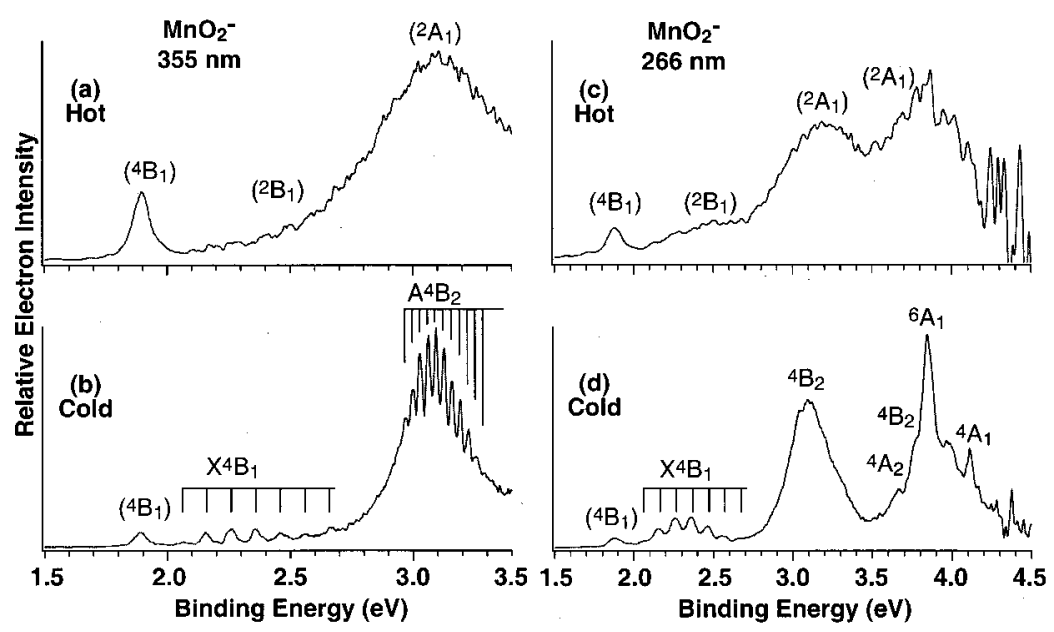

FIG. 8. Photoelectron spectra of $\mathrm{MnO}_{2}^{-}$at $355 \mathrm{~nm}$ $(3.496 \mathrm{eV})$ and $266 \mathrm{~nm}(4.661 \mathrm{eV})$. (a) At $355 \mathrm{~nm}$ and under "hot" experimental conditions; (b) at $355 \mathrm{~nm}$ and under "cold" experimental conditions; (c) at 266 $\mathrm{nm}$ and under "hot" experimental conditions; (d) at $266 \mathrm{~nm}$ and under "cold" experimental conditions. 
TABLE VI. Summary of experimental and theoretical adiabatic electron affinities $\left(A_{\mathrm{ea}}\right)$, calculated according to Eq. (3) and vibrational frequencies of neutral $\mathrm{MnO}_{x}$. All energies are in $\mathrm{eV}$ and vibrational frequencies in $\mathrm{cm}^{-1}$.

\begin{tabular}{lccllll}
\hline \hline & \multicolumn{2}{c}{$A_{\text {ea }}$} & & \multicolumn{2}{c}{ Vib. freq. } \\
\cline { 2 - 3 } \cline { 6 - 6 } & Theory & \multicolumn{1}{c}{ Expt. } & & Theory & Expt. \\
\hline $\mathrm{O}^{\mathrm{a}}$ & 1.63 & 1.46 & & & \\
$\mathrm{Mn}^{\mathrm{a}}$ & 0.05 & 0.00 & & & \\
$\mathrm{O}_{2}{ }^{\mathrm{a}}$ & 0.47 & $0.451(0.007)$ & & & \\
$\mathrm{MnO}$ & 1.05 & $1.375(0.010)$ & & $898^{\mathrm{c}}$ & $820(40)^{\mathrm{c}}$ \\
$\mathrm{MnO}_{2}$ & 2.01 & $2.06(0.03)$ & & 918 & $800(40)$ \\
$\mathrm{MnO}_{3}$ & 3.21 & $3.335(0.010)$ & & 926 & $840(50)$ \\
$\mathrm{MnO}_{4}{ }^{\mathrm{f}}$ & 4.96 & $4.80(0.10)$ & & & \\
\hline \hline
\end{tabular}

Reference 31.

${ }^{\mathrm{b}}$ Reference 74.

${ }^{\mathrm{c}}$ Current work.

${ }^{\mathrm{d}}$ Reference 45 .

${ }^{\mathrm{e}}$ Reference 42.

${ }^{\mathrm{f}}$ Reference 29.

\section{Spectral assignments and comparison to the theoretical calculations}

\section{1. $\mathrm{MnO}$ and $\mathrm{MnO}^{-}: 532 \mathrm{~nm}$}

The "cold" spectrum of $\mathrm{MnO}^{-}$at $532 \mathrm{~nm}$ [Fig. 6(b)] contains a well-resolved vibrational progression. The strongest peak at $1.375(0.010) \mathrm{eV}$ is identified as the $0-0$ transition and the vibrational progression gives an average spacing of $820(40) \mathrm{cm}^{-1}$. The peaks to the left of the $0-0$ transition are due to hot band transitions (HB) from vibrationally excited $\mathrm{MnO}^{-}$anions, yielding an average vibrational frequency of $760(50) \mathrm{cm}^{-1}$ for $\mathrm{MnO}^{-}$. There are also several weak features beyond $2 \mathrm{eV}$ in the "cold" spectrum [Fig. 6(b)]. The vibrational progression should be due to detachment transitions from the ground state of $\mathrm{MnO}^{-}$to that of $\mathrm{MnO}$, i.e., $\left.\mathrm{MnO}^{-}\left({ }^{5} \Sigma^{+}\right) \rightarrow \mathrm{MnO}^{6}{ }^{6} \Sigma^{+}\right)+e^{-}$. Our measured electron affinity of $1.375 \mathrm{eV}$ for $\mathrm{MnO}$ compares reasonably well to the theoretical value of $1.05 \mathrm{eV}$ (Table VI). The obtained vibrational frequency $\left(820 \pm 40 \mathrm{~cm}^{-1}\right)$ for the ground state of $\mathrm{MnO}$ is in excellent agreement with the previously known value of $840 \mathrm{~cm}^{-1}$. Our measured vibrational frequencies for the ground states of both the neutral and the anion are in reasonable agreement with the current theoretical values (Table I), which apparently overestimate the vibrational frequency of $\mathrm{MnO}$.

Two changes are immediately recognized in the "hot", spectrum of $\mathrm{MnO}^{-}$[Fig. 6(a)]. First, the vibrational peaks become broad, and, second, the higher binding energy features labeled as ${ }^{6} \Pi_{i}$ are enhanced. Our calculations predict that $\mathrm{MnO}^{-}$has an excited state (Tables I and IV), which is only $0.14 \mathrm{eV}$ above the $\mathrm{MnO}^{-}$ground state. The extra electron in the ground state of $\mathrm{MnO}^{-}$fills a $3 d-\sigma\left(9 \sigma^{\beta}\right) \mathrm{MO}$, resulting in the ${ }^{5} \Sigma^{+}$state, whereas the extra electron in the excited state occupies a mostly $4 s \mathrm{MO}\left(10 \sigma^{\alpha}\right)$, giving rise to the ${ }^{7} \Sigma^{+}$state. Our data suggest that the excited anions were present in the anion beams. However, the presence of the hot band features makes it difficult to recognize the $0-0$ transition for the excited state. Our assignment in Fig. 6(a) is based on the theoretical excitation energy of $0.14 \mathrm{eV}$ for the excited state. From Table I, we can see that the ${ }^{7} \Sigma^{+}$state has a substantially longer bond length than the ground state, suggesting that the vibrational progression due to the excited state of $\mathrm{MnO}^{-}$should be broader, which is consistent with the general appearance of the observed spectrum.

To confirm these assignments and gain further information about the approximate anion temperatures, we carried out Franck-Condon simulations of the vibrationally resolved spectral features. The simulated spectra are shown in Fig. 6 as dotted and dashed curves. A temperature of about $1000 \mathrm{~K}$ had to be used to reproduce the hot band features in the "cold" spectrum [Fig. 6(b)], consistent with our experience that diatomic anions are generally difficult to cool in our cluster source. A temperature of about $2000 \mathrm{~K}$ was used to simulate the hot spectrum. We also obtained the approximate bond lengths of the two anion states, $1.68 \AA$ for the ${ }^{5} \Sigma^{+}$ state and $1.84 \AA$ for the ${ }^{7} \Sigma^{+}$state. These results suggest that the theoretical calculations underestimated the bond lengths of the anions, as is also the case for the neutral ground state (Table I).

The features beyond $2 \mathrm{eV}$, which are enhanced in the " "hot" spectrum, should come also from the excited state of $\mathrm{MnO}^{-}$. The fact that the excited state has a different multiplicity than the ground state makes the excited state rather long-lived; the above Franck-Condon simulations suggest that even under the "cold" experimental condition the $\mathrm{MnO}^{-}$anions were still relatively hot. These two factors probably contribute to the substantial population of the electronically excited $\mathrm{MnO}^{-}$even under the "cold" condition. This is more clearly demonstrated in the 355 and $266 \mathrm{~nm}$ spectra (Fig. 7), where more spectral features were observed. The spectra at 355 and $266 \mathrm{~nm}$ indicate in fact that the electronically excited $\mathrm{MnO}^{-}$was dominant under the "hot" conditions [Figs. 7(a) and 7(c)].

\section{2. $\mathrm{MnO}$ and $\mathrm{MnO}^{-}: 355$ and $266 \mathrm{~nm}$}

The "cold" and "hot" spectra of $\mathrm{MnO}^{-}$obtained at 355 and $266 \mathrm{~nm}$ are shown in Fig. 7. The features between 2.1 and $2.3 \mathrm{eV}$, that were observed at $532 \mathrm{~nm}$ (Fig. 6), are more prominent at 355 and $266 \mathrm{~nm}$ and exhibit a very strong temperature dependence with much stronger intensity in the "hot" spectra [Figs. 7(a) and 7(c)]. There are numerous higher binding energy features that are revealed in the higher photon energy spectra. Strong temperature effects allow us to associate the different features to either the ground or excited states of $\mathrm{MnO}^{-}$.

As mentioned above, the features between $2.1-2.3 \mathrm{eV}$ should be due to the excited state of $\mathrm{MnO}^{-}$. From our theoretical calculations (Table IV), these features should be due to removal of a $4 \pi^{\alpha}$ electron from the ${ }^{7} \Sigma^{+}$state of $\mathrm{MnO}^{-}$, resulting in a ${ }^{6} \Pi$ final state of $\mathrm{MnO}$. The observed features are assigned to different spin-orbit components of this state, as shown in Fig. 7(a) and Table IV.

The feature at $2.45 \mathrm{eV}$ seems to have a short vibrational progression with a $660 \mathrm{~cm}^{-1}$ spacing [Fig. 7(b)]. The relative intensity of this feature is significantly reduced in the "hot" spectra at both 355 [Fig. 7(a)] and $266 \mathrm{~nm}$ [Fig. 7(c)]. We thus attribute the $2.45 \mathrm{eV}$ feature to have arisen from the ground state of $\mathrm{MnO}^{-}$, representing the second detachment 
channel from the ground state of $\mathrm{MnO}^{-}$. According to our theoretical results (Table IV), this corresponds to removal of a $4 \pi^{\alpha}$ electron with a resulting ${ }^{4} \Pi$ state of $\mathrm{MnO}$. The ${ }^{4} \Pi$ state should have several spin-orbit components. However, they were not observed, possibly because the splittings are too small to be resolved.

The next higher binding energy features are located between 2.6 and $3.1 \mathrm{eV}$ and consist of five sharp peaks in the "cold" $355 \mathrm{~nm}$ spectrum [Fig. 7(b)]. This group of peaks should be due to detachment of the ground state $\mathrm{MnO}^{-}$because their relative intensity is significantly reduced in the "hot" spectra. These peaks correspond to a vibrational progression with a spacing of $920 \mathrm{~cm}^{-1}$. The two lower binding energy features are due to hot band transitions, which yield a vibrational spacing for the $\mathrm{MnO}^{-}$anion, identical to that derived from the "cold" $532 \mathrm{~nm}$ spectrum [Fig. 6(b)]. According to our calculations, these features should be due to removal of a $9 \sigma^{\alpha}$ electron, resulting in a ${ }^{4} \Sigma^{+}$final state of $\mathrm{MnO}$ as shown in Table IV and Fig. 7.

Three more features are observed in the $355 \mathrm{~nm}$ spectra in the $3.2-3.5 \mathrm{eV}$ region. They are significantly enhanced in the "hot" spectrum, and thus are due to the excited state of $\mathrm{MnO}^{-}$. The $266 \mathrm{~nm}$ spectra show that these features are related to a vibrational progression with the two lower binding energy features coming from hot band transitions. The average spacing of the hot bands is $730(50) \mathrm{cm}^{-1}$, which should correspond to the vibrational frequency of the $\mathrm{MnO}^{-}$ excited state. We note that this spacing is identical to that due to the ground state of $\mathrm{MnO}^{-}$. From our theoretical results given in Table I, the ${ }^{5} \Sigma^{+}$and ${ }^{7} \Sigma^{+}$states have very similar vibrational frequencies, consistent with our experimental observations. According to our theoretical results (Table IV), this detachment channel should be due to removal of a $9 \sigma^{\alpha}$ electron from the ${ }^{7} \Sigma^{+}$excited state of $\mathrm{MnO}^{-}$, giving rise to a ${ }^{6} \Sigma^{+}$final state of $\mathrm{MnO}$. We also note that the peak near $3.6 \mathrm{eV}$ seems to be quite intense in the "cold" 266 nm spectrum [Fig. 7(d)] and it becomes negligible in the "hot" spectrum [Fig. 7(c)]. According to our theoretical results, we tentatively assign this feature to a ${ }^{6} \Pi$ state, due to removal of a $3 \pi^{\beta}$ electron from the ground state of $\mathrm{MnO}^{-}$.

Therefore, we have observed three excited states $\left({ }^{4} \Pi,{ }^{4} \Sigma^{+},{ }^{6} \Pi\right)$ for $\mathrm{MnO}$ due to detachment from the ground state of $\mathrm{MnO}^{-}$and two excited states $\left({ }^{6} \Pi,{ }^{6} \Sigma^{+}\right)$for $\mathrm{MnO}$ due to detachment from the excited state of $\mathrm{MnO}^{-}$. These states are indicated in Fig. 7 and are compared to the theoretical results in Table IV. We note that the theoretical binding energies are all lower than the experimental values by $0.2-0.6 \mathrm{eV}$. This discrepancy is probably not surprising, considering the complexity of the $\mathrm{MnO}$ systems. The excited state manifold of $\mathrm{MnO}$ is not very well known and our assignment should be viewed as tentative. Definitive assignments appear to require more accurate calculations for the $\mathrm{MnO}-\mathrm{MnO}^{-}$pair, which contains partially occupied degenerate MOs.

\section{3. $\mathrm{MnO}_{2}$ and $\mathrm{MnO}_{2}^{-}$}

The $\mathrm{MnO}_{2}^{-}$spectrum also shows very strong temperature effects. In the "cold" $355 \mathrm{~nm}$ spectrum [Fig. 8(b)], a weak feature near $1.89 \mathrm{eV}$ was observed, followed by a weak and broad vibrational progression with an $800 \mathrm{~cm}^{-1}$ average spacing. A strong and broad vibrational progression was observed at about $3 \mathrm{eV}$ with an average spacing of $260 \mathrm{~cm}^{-1}$. In the "hot" $355 \mathrm{~nm}$ spectrum [Fig. 8(a)], the $1.89 \mathrm{eV}$ feature was significantly enhanced, whereas the two wellresolved vibrational progressions observed in the "cold" spectrum disappeared and were replaced by featureless broad bands. In the "cold" $266 \mathrm{~nm}$ spectrum [Fig. 8(d)], numerous high binding energy features were observed between 3.5 and $4.5 \mathrm{eV}$, whereas again in the "hot" $266 \mathrm{~nm}$ spectrum the $1.89 \mathrm{eV}$ feature was enhanced and the higher binding energy features all became unresolved broad bands.

Such a temperature dependence of the $\mathrm{MnO}_{2}^{-}$spectra suggests that some isomers are present in the anion beams. The $1.89 \mathrm{eV}$ feature should be due to a higher energy isomer, which could be more populated or predominate under the "hot" conditions. The main features in the "cold" spectra should be all due to the ground state $\mathrm{MnO}_{2}^{-}$species. The vibrational progression between $2.0-2.7 \mathrm{eV}$ yields 2.06 and $2.26 \mathrm{eV}$ for the adiabatic and vertical detachment energies from the ground state $\mathrm{MnO}_{2}^{-}$.

Our theoretical calculations predict that $\mathrm{MnO}_{2}$ is a highvalent $C_{2 v}$ molecule with a ${ }^{4} B_{1}$ ground state and an electron configuration, $11 a_{1}^{1} 10 a_{1}^{1} 4 b_{1}^{1} 1 a_{2}^{2} 6 b_{2}^{2}$. In the ground state of $\mathrm{MnO}_{2}^{-}$, the extra electron fills the $2 a_{2} \mathrm{HOMO}$ of $\mathrm{MnO}_{2}$, leading to a ${ }^{5} B_{2}$ state for $\mathrm{MnO}_{2}^{-}$. There are also two lowlying excited states predicted for $\mathrm{MnO}_{2}^{-}$(Table II). The first one is a ${ }^{3} B_{1}$ state, which is only $0.15 \mathrm{eV}$ higher, followed by $\mathrm{a}^{3} A_{1}$ state, which is $0.31 \mathrm{eV}$ above the ground state.

Our measured adiabatic $(2.06 \mathrm{eV})$ and vertical $(2.26 \mathrm{eV})$ binding energies for the ground state of $\mathrm{MnO}_{2}^{-}$are in excellent agreement with the theoretical values (Table V). The observed vibrational progression should be due to the $\mathrm{Mn}-\mathrm{O}$ symmetric stretching vibration, which is also consistent with the theoretical calculations that there is a substantial $\mathrm{Mn}-\mathrm{O}$ bond length change between the ground states of $\mathrm{MnO}_{2}$ and $\mathrm{MnO}_{2}^{-}$, whereas their bond angles are nearly the same (Table II). The measured vibrational frequency of $800 \mathrm{~cm}^{-1}$ for $\mathrm{MnO}_{2}$ is in reasonable agreement with the theoretical value of $918 \mathrm{~cm}^{-1}$, which again seems to be overestimated.

The vibrationally resolved band near $3 \mathrm{eV}$ should be due to removal of an $11 a_{1}$ electron from the ground state of $\mathrm{MnO}_{2}^{-}$, giving a ${ }^{4} B_{2}$ state. The resolved vibrational structure should be due to the $\mathrm{MnO}_{2}$ bending mode, suggesting a large bond angle change upon removing a $11 a_{1}$ electron. Our measured vertical binding energy of $3.09 \mathrm{eV}$ is in good agreement with the theoretical value of $3.39 \mathrm{eV}$ (Table V). The calculations predict that there should be four detachment channels within a narrow energy range between 3.9-4.4 eV. This prediction is consistent with the observation of the "cold" $266 \mathrm{~nm}$ spectrum [Fig. 8(d)], which revealed several features between 3.5-4.3 eV. However, exact assignments are not possible here because the spectrum is congested and may contain overlapping features. Tentative assignments are made, as shown in Fig. 8(d). All of the observed features due to detachment from the ground state of $\mathrm{MnO}_{2}^{-}$are compared 
with the theoretical calculations in Table $\mathrm{V}$.

The two low energy isomers of $\mathrm{MnO}_{2}^{-}$possess very similar detachment energies and spectral patterns. The ${ }^{3} B_{1}$ isomer gives a vertical binding energy of $1.88 \mathrm{eV}$, which is almost exactly the same as the experimental value of 1.89 $\mathrm{eV}$. The ${ }^{3} A_{1}$ isomer, which is about $0.16 \mathrm{eV}$ higher in energy above the ${ }^{3} B_{1}$ isomer, gives a vertical binding energy of 1.84 $\mathrm{eV}$, which is also in excellent agreement with the experimental value. However, their adiabatic binding energies are quite different as can be obtained from the $E_{\text {tot }}$ in Table II. The ${ }^{3} B_{1}$ isomer gives an adiabatic binding energy of $1.85 \mathrm{eV}$, which is in excellent agreement with the experimental estimate of $1.84 \pm 0.03 \mathrm{eV}$. On the other hand, the ${ }^{3} A_{1}$ isomer gives an adiabatic binding energy of $1.70 \mathrm{eV}$. Based on this observation and energetic considerations, we conclude that the observed isomer of $\mathrm{MnO}_{2}^{-}$in our experiment is the ${ }^{3} B_{1}$ species. Even though only broad bands were observed for the higher binding energy detachment channels for the ${ }^{3} B_{1}$ isomer [Figs. 8(a) and 8(c)], the estimated binding energies are in good agreement with the theoretical values as compared in Table V.

\section{4. $\mathrm{MnO}_{3}$ and $\mathrm{MnO}_{3}^{-}$}

Our theoretical calculations predict that $\mathrm{MnO}_{3}^{-}$possesses $D_{3 h}$ symmetry with a singlet ground state (Fig. 5). The lowest energy isomer is a triplet state $0.33 \mathrm{eV}$ higher in energy. Our photoelectron spectrum of $\mathrm{MnO}_{3}^{-}$at $266 \mathrm{~nm}$ revealed only a single vibrationally resolved band, with an $840 \mathrm{~cm}^{-1}$ vibrational spacing and an adiabatic binding energy of 3.335 $\mathrm{eV}$. No indication of an isomer was observed. Therefore, the observed features were assigned to detachment transitions from the ground state of $\mathrm{MnO}_{3}^{-}$to that of $\mathrm{MnO}_{3}$. The observed binding energy is in very good agreement with the calculated value of $3.21 \mathrm{eV}$ (Table VI). The observed short vibrational progression should be due to symmetric $\mathrm{Mn}-\mathrm{O}$ vibrations, consistent with moderate $\mathrm{Mn}-\mathrm{O}$ bond length changes between the ground state of $\mathrm{MnO}_{3}^{-}$and $\mathrm{MnO}_{3}$ (see Figs. 4 and 5).

In Table VI, we summarize all the experimental electron affinities of $\mathrm{MnO}_{x}(x=1-4)$, their stretching vibrational frequencies, and the electron affinities of $\mathrm{O}, \mathrm{Mn}$, and $\mathrm{O}_{2}$, compared to theoretical values obtained currently. Except for $\mathrm{MnO}$, which has five unpaired $3 d$ electrons and many lowlying states, the theoretical electron affinities are all in very good agreement with the experimental measurements. The theoretical vibrational frequencies obtained currently seem to be over estimated in all cases, relative to the experimental values (Table VI).

\section{SUMMARY}

We report a comprehensive theoretical and experimental investigation of $\mathrm{MnO}_{x}^{-}(x=1-3)$ and their corresponding neutral species. Photodetachment photoelectron spectra were obtained for the anions produced from a laser vaporization cluster source at various photon energies. Numerous features with strong temperature dependence were observed in the spectra of $\mathrm{MnO}^{-}$and were attributed to the presence of an excited state of the anion. This excited state of $\mathrm{MnO}^{-}$was

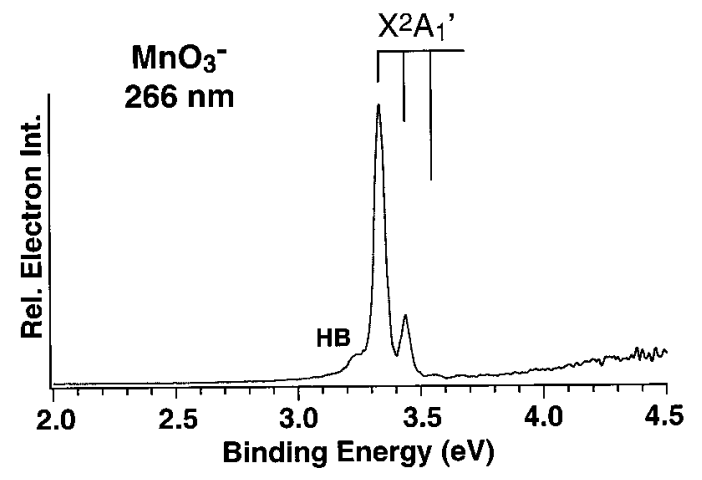

FIG. 9. Photoelectron spectrum of $\mathrm{MnO}_{3}^{-}$at $266 \mathrm{~nm}(4.661 \mathrm{eV})$. " $\mathrm{HB}$ ", indicates hot band transitions.

observed to be predominant at higher source temperatures. The ground state of $\mathrm{MnO}^{-}$was predicted to be ${ }^{5} \Sigma^{+}$and the excited state to be ${ }^{7} \Sigma^{+}$, about $0.14 \mathrm{eV}$ above the ground state. Various one-electron photodetachment channels were calculated and used to interpret the observed complicated photodetachment features. The $\mathrm{MnO}_{2}^{-}$spectra also exhibited a strong temperature dependence, which was found to be due to the presence of two isomers of the anion. Theoretical calculations predicted that the ground state of $\mathrm{MnO}_{2}^{-}$is a highvalent $(\mathrm{OMO})$ and high-spin state $\left({ }^{5} B_{2}\right)$. The lowest isomer of $\mathrm{MnO}_{2}^{-}$has a triplet ${ }^{3} B_{1}$ state and is higher by $0.15 \mathrm{eV}$. Various one-electron detachment channels of the two isomers of $\mathrm{MnO}_{2}^{-}$were calculated and compared to the experimental findings. Only one isomer was observed for $\mathrm{MnO}_{3}^{-}$, which gave a single detachment band corresponding to transitions from the ground state of the anion to that of the neutral. Theoretical calculations predict that the ground state of $\mathrm{MnO}_{3}^{-}$has $D_{3 h}$ symmetry with a ${ }^{1} A_{1}^{\prime}$ term, whereas the ground state of the neutral is a $C_{3 v}$ species with a ${ }^{2} A_{1}$ term. Calculated adiabatic and vertical binding energies of $\mathrm{MnO}_{3}^{-}$ are in excellent agreement with the experimental values. We show that theoretical calculations are very helpful in interpretations of the photoelectron spectra of the complicated $\mathrm{MnO}_{x}^{-}$anions, and in understanding the electronic and geometrical structures and chemical bonding in both the anions and the neutral species.

\section{ACKNOWLEDGMENTS}

We thank Dr. Hai-Feng Zhang for the Franck-Condon simulations. This work was supported in part by a grant to Virginia Commonwealth University by the Department of Energy (Grant No. DE-FG02-96ER45579). The experimental work was supported by NSF (to L.S.W.) under Grant No. CHE-9817811 and performed at the W. R. Wiley Environmental Molecular Sciences Laboratory, a national scientific user facility sponsored by Department of Energy's Office of Biological and Environmental Research and located at $\mathrm{Pa}-$ cific Northwest National Laboratory. Pacific Northwest National laboratory is operated for the U.S. Department of Energy by Battelle. L.S.W. is an Alfred P. Sloan Foundation Research Fellow. 
${ }^{1}$ C. N. R. Rao and B. Ravenau, Transition Metal Oxides (CVCH, New York, 1995).

${ }^{2}$ X. G. Zhao, W. H. Richardson, J.-L. Chen, J. Li, L. Noodleman, H.-L. Tsai, and D. N. Hendrickson, Inorg. Chem. 36, 1198 (1997).

${ }^{3}$ L. M. Ioffe, T. Lopez, Yu. G. Borod'ko, and R. Gomez, J. Mol. Catal. A: Chem. 98, 25 (1995).

${ }^{4}$ F. A. Cotton and G. Wilkinson, Advanced Inorganic Chemistry (WileyInterscience, New York, 1988).

${ }^{5}$ J. H. Mathews and L. H. Dewey, J. Phys. Chem. 17, 211 (1913).

${ }^{6}$ S. K. Nayak and P. Jena, Phys. Rev. Lett. 81, 2970 (1998).

${ }^{7}$ S. Y. Wang, L.-J. Zou, X. G. Gong, Q. Q. Zheng, and H. Q. Lin, J. Appl. Phys. 83, 7100 (1998).

${ }^{8}$ S. K. Nayak and P. Jena, J. Am. Chem. Soc. 121, 644 (1999).

${ }^{9}$ M. R. Pederson and S. N. Khanna, Phys. Rev. B 59, R693 (1999).

${ }^{10}$ G. Palenik, Inorg. Chem. 6, 503 (1967).

${ }^{11}$ H. Homborg, Z. Anorg, Z. Anorg. Allg. Chem. 498, 25 (1983).

${ }^{12}$ A. Müller and E. Diemann, Chem. Phys. Lett. 9, 369 (1971).

${ }^{13}$ L. W. Johnson and S. P. McGlynn, Chem. Phys. Lett. 10, 595 (1971).

${ }^{14}$ T. Ziegler, A. Rauk, and E. J. Baerends, Chem. Phys. 16, 209 (1976).

${ }^{15}$ G. L. Gutsev and A. A. Levin, Struct. Chem. 19, 838 (1979).

${ }^{16}$ R. M. Dickson and T. Ziegler, Int. J. Quantum Chem. 58, 681 (1996).

${ }^{17}$ A. C. Stücl and H. U. Güdel, Int. J. Quantum Chem. 61, 579 (1997).

${ }^{18}$ S. J. A. van Gisbergen, J. A. Groeneveld, A. Rosa, J. G. Snijders, and E. J. Baerends, J. Phys. Chem. 103, 6835 (1999).

${ }^{19}$ H. Johansen, Mol. Phys. 49, 1209 (1983).

${ }^{20}$ M. A. Buijse and E. J. Baerends, J. Chem. Phys. 93, 4129 (1990).

${ }^{21}$ E. K. Rideal and R. G. W. Norrish, Proc. R. Soc. London, Ser. A 103, 342 (1923).

${ }^{22}$ A. L. S. Rao, Proc. Indian Acad. Sci. 6A, 293 (1937).

${ }^{23}$ G. Zimmerman, J. Chem. Phys. 23, 825 (1955).

${ }^{24}$ U. Kläning and M. C. R. Symons, J. Chem. Soc. 1959, 3269.

${ }^{25}$ D. G. Lee, C. R. Moylan, T. Hayashi, and J. I. Brauman, J. Am. Chem. Soc. 109, 3003 (1987).

${ }^{26}$ H. Nakai and H. Nakatsuji, J. Phys. Chem. 99, 8550 (1995).

${ }^{27}$ G. L. Gutsev, B. K. Rao, and P. Jena, J. Phys. Chem. A 103, 10819 (1999).

${ }^{28}$ G. L. Gutsev and A. I. Boldyrev, Chem. Phys. Lett. 108, 255 (1984).

${ }^{29}$ G. L. Gutsev, B. K. Rao, P. Jena, X. B. Wang, and L. S. Wang, Chem. Phys. Lett. 312, 598 (1999).

${ }^{30}$ G. L. Gutsev and A. I. Boldyrev, Adv. Chem. Phys. 61, 169 (1985).

${ }^{31}$ H. Hotop and W. C. Lineberger, J. Phys. Chem. Ref. Data 14, 731 (1985).

${ }^{32}$ R. R. Squires, Chem. Rev. 87, 623 (1987).

${ }^{33}$ R. H. Fokkens, I. K. Gregor, and N. M. M. Nibbering, Rapid Commun. Mass Spectrom. 5, 368 (1991).

${ }^{34}$ E. B. Rudnyi, E. A. Kaibicheva, and L. N. Sidorov, Rapid Commun. Mass Spectrom. 7, 800 (1993).

${ }^{35}$ R. F. Ferrante, J. L. Wilkerson, W. R. M. Graham, and W. Weltner, Jr., J. Chem. Phys. 67, 5904 (1977).

${ }^{36}$ L. V. Serebrennikov and A. A. Maltsev, Vestn. Mosk. Univ., Ser. 2: Khim. 2, 148 (1980).

${ }^{37}$ M. J. Almond, J. Mol. Struct. 172, 157 (1988).

${ }^{38}$ G. V. Chertihin and L. Andrews, J. Phys. Chem. 101, 8547 (1997).

${ }^{39}$ D. Schröder, A. Fiedler, J. Schwarz, and H. Schwarz, Inorg. Chem. 33, 5094 (1994).

${ }^{40}$ G. L. Gutsev, B. K. Rao, and P. Jena (unpublished).

${ }^{41}$ K. P. Huber and G. Herzberg, Constants of Diatomic Molecules (Van Nostrand-Reinhold, New York, 1979).
${ }^{42}$ R. M. Gordon and A. L. Merer, Can. J. Phys. 88, 642 (1980).

${ }^{43}$ A. J. Merer, Annu. Rev. Phys. Chem. 40, 407 (1989).

${ }^{44}$ M. Dolg, U. Wedig, H. Stoll, and H. Preuss, J. Chem. Phys. 86, 2123 (1987).

${ }^{45}$ C. W. Bauschlicher, Jr. and P. Maitre, Theor. Chim. Acta 90, 189 (1995).

${ }^{46}$ A. Pramann and K. Rademann, Int. J. Mass. Spectrom. 187, 673 (1999).

${ }^{47} \mathrm{~L}$. S. Wang and H. Wu, in Advances in Metal and Semiconductor Clusters. IV. Cluster Materials, edited by M. A. Duncan (JAI, Greenwich, CT, 1998), p. 299.

${ }^{48}$ L. S. Wang, C. F. Ding, X. B. Wang, and S. E. Barlow, Rev. Sci. Instrum. 70, 1957 (1999).

${ }^{49}$ L. S. Wang, in Advanced Series in Physical Chemistry, edited by C. Y. Ng (World Scientific, Singapore, 2000), Vol. 10, Chap. XVI.

${ }^{50}$ J. Fan and L. S. Wang, J. Chem. Phys. 102, 8714 (1995).

${ }^{51}$ H. Wu, S. R. Desai, and L. S. Wang, J. Chem. Phys. 103, 4363 (1995).

${ }^{52}$ L. S. Wang, H. Wu, S. R. Desai, and L. Lou, Phys. Rev. B 53, 8028 (1996).

${ }^{53}$ H. Wu, S. R. Desai, and L. S. Wang, J. Am. Chem. Soc. 118, 5296 (1996).

${ }^{54}$ H. Wu, S. R. Desai, and L. S. Wang, J. Phys. Chem. A 101, 2103 (1997).

${ }^{55} \mathrm{H}$. Wu and L. S. Wang, J. Chem. Phys. 107, 16 (1997).

${ }^{56} \mathrm{H}$. Wu and L. S. Wang, J. Chem. Phys. 107, 8221 (1997).

${ }^{57}$ H. Wu and L. S. Wang, J. Chem. Phys. 108, 5310 (1998).

${ }^{58}$ H. Wu and L. S. Wang, J. Phys. Chem. A 102, 9129 (1998).

${ }^{59}$ A. D. Becke, Phys. Rev. A 38, 3098 (1988).

${ }^{60}$ J. P. Perdew and Y. Wang, Phys. Rev. B 45, 13244 (1991).

${ }^{61}$ Gaussian 94, Revision B.1, M. J. Frisch, G. W. Trucks, H. B. Schlegel, P. M. W. Gill, B. G. Johnson, M. A. Robb, J. R. Cheeseman, T. Keith, G. A. Petersson, J. A. Montgomery, K. Raghavachari, M. A. Al-Laham, V. G. Zakrzewski, J. V. Ortiz, J. B. Foresman, J. Cioslowski, B. B. Stefanov, A. Nanayakkara, M. Challacombe, C. Y. Peng, P. Y. Ayala, W. Chen, M. W. Wong, J. L. Andres, E. S. Replogle, R. Gomperts, R. L. Martin, D. J. Fox, J. S. Binkley, D. J. Defrees, J. Baker, J. P. Stewart, M. Head-Gordon, C. Gonzalez, and J. A. Pople, Gaussian Inc., Pittsburgh, Pennsylvania.

${ }^{62}$ G. L. Gutsev, S. N. Khanna, B. K. Rao, and P. Jena, Phys. Rev. A 59, 3681 (1999)

${ }^{63}$ G. L. Gutsev, S. N. Khanna, B. K. Rao, and P. Jena, J. Phys. Chem. 103, 5812 (1999)

${ }^{64}$ G. L. Gutsev, B. V. Reddy, S. N. Khanna, B. K. Rao, and P. Jena, Phys. Rev. B 58, 14131 (1998).

${ }^{65}$ W. Kohn and L. J. Sham, Phys. Rev. 140, A1133 (1965).

${ }^{66}$ O. Gunnarsson and B. I. Lundqvist, J. Chem. Phys. 13, 4274 (1976).

${ }^{67}$ E. K. U. Gross, L. N. Oliveira, and W. Kohn, Phys. Rev. A 37, 2809 (1988).

${ }^{68}$ G. L. Gutsev, R. J. Bartlett, and R. N. Compton, J. Chem. Phys. 108, 6756 (1998).

${ }^{69}$ G. L. Gutsev and R. J. Bartlett, Mol. Phys. 94, 121 (1998).

${ }^{70}$ L. S. Wang, H. S. Cheng, and J. Fan, J. Chem. Phys. 102, 9480 (1995).

${ }^{71}$ J. Akola, M. Manninen, H. Hakkinen, U. Landman, X. Li, and L. S. Wang, Phys. Rev. B 60, 11297 (1999).

${ }^{72} \mathrm{~L}$. S. Wang and X. Li, in Proceedings of the International Symposium on Clusters and Nanostructure Interfaces, edited by P. Jena, S. N. Khanna, and B. K. Rao (World Scientific, New Jersey, 2000).

${ }^{73}$ X. Li and L. S. Wang, J. Chem. Phys. 109, 5264 (1998).

${ }^{74}$ M. J. Travers, D. C. Cowles, and G. B. Ellison, Chem. Phys. Lett. 164, 449 (1989). 